\title{
Civilisations
}

Revue internationale d'anthropologie et de sciences

humaines

$65 \mid 2016$

Figures du malentendu

\section{Working misunderstandings and notions of collaboration}

Towards a framework of working misunderstanding as analytical category for ethnographic insight

\section{Frauke Mörike}

\section{(2) OpenEdition \\ 12 Journals}

\section{Electronic version}

URL: http://journals.openedition.org/civilisations/4081

DOI: 10.4000/civilisations.4081

ISSN: 2032-0442

\section{Publisher}

Institut de sociologie de l'Université Libre de Bruxelles

\section{Printed version}

Date of publication: 19 December 2016

Number of pages: $145-160$

ISBN: 2-9602017-0-3

ISSN: 0009-8140

\section{Electronic reference}

Frauke Mörike, "Working misunderstandings and notions of collaboration ", Civilisations [Online], 65 |

2016, Online since 19 December 2019, connection on 15 January 2021. URL: http://

journals.openedition.org/civilisations/4081 ; DOI: https://doi.org/10.4000/civilisations.4081

(c) Tous droits réservés 


\title{
Working misunderstandings and notions of collaboration
}

\author{
Towards a framework of working misunderstanding as analytical category \\ for ethnographic insight
}

\author{
Frauke MÖRIKE
}

\begin{abstract}
In a direct sense of the word, a "mis"-understanding is an understanding, but not in the "right" normatively expected direction. It therefore enables access to diverging viewpoints of the interacting parties. Consequently, misunderstandings can be regarded as an opportunity rather than a threat to ethnographic insight. By introducing the concept of working misunderstandings, this article illustrates in fact their productive (positive) role to facilitate social interaction on the basis of various accounts from literature. Derived from the diverging applications of the concept in ethnographic studies, a quadrant typology is proposed to structure working misunderstandings as analytical category. The suggested framework aims to facilitate a more precise discussion on working misunderstandings and their systematic employment in ethnographic research. The ethnographic example deals with a working misunderstanding between the anthropologist and her interlocutors on "collaboration" in a multi-national professional servicing firm in Mumbai, India.
\end{abstract}

Keywords: working misunderstanding, collaboration, multi-national organisation, fieldwork, Mumbai.

Résumé : Littéralement, le malentendu (mis-understanding) est une forme de compréhension (understanding), mais dans une direction ne correspondant pas à la norme anticipée. Il permet dès lors d'accéder aux points de vue divergents des parties qui interagissent. Les malentendus sont dès lors plus une opportunité qu'une menace pour la recherche ethnographique. Sur base d'exemples puisés dans la littérature ethnographique, cet article reprend le concept de malentendus productifs (working misunderstandings) et illustre leur rôle positif pour faciliter les interactions sociales. Les usages variés du concept apparaissant dans cette littérature ont permis d'élaborer une typologie en quadrant des cas de figure. Ceci permet d'analyser avec plus de précision les références au malentendu productif et leur usage dans la recherche ethnographique. Le travail de terrain de l'auteur est mobilisé pour montrer comment un malentendu productif relatif à la " collaboration » a évolué, entre l'ethnographe et ses interlocuteurs, dans un multinationale de sous-traitance installée à Mumbay.

Mots-clés : malentendu productif, collaboration, multinationale, enquête ethnographique, Mumbai. 


\section{Accepting misunderstanding}

The prefix "mis" to the word understanding indicates negative meaning such as "wrong" or "deficient". Misunderstanding, however, neither constitutes the direct opposite of understanding, nor could it be doubtlessly located in the area of not understanding: although often used in everyday language synonymously, it is indeed a significant difference if someone has not understood or misunderstood a circumstance. In a misunderstanding, a process of understanding took place on the basis of an input received, but not in the normatively expected direction from the perspective of the person judging the misunderstanding. Due to the existence of a normatively correct possibility of understanding, a misunderstanding is regarded in common views as a failure to understand (as well as not understanding is) and therefore perceived as something to be avoided. But as the misunderstanding delineates an alternative understanding of an utterance or a situation in contrast to the "right" (i.e. the normatively expected) direction, it depicts a highly valuable source of information about the perspectives of the interacting parties. It denotes a boundary zone where "les cultures s'expliquent et se confrontent, se découvrant différentes" (La Cecla, 2002:14) - where cultures get into explanation and confrontation, and discover their differences.

Therefore misunderstandings can be regarded as an opportunity rather than a threat to ethnographic insight. Following this proposition, the article focuses on the productive (positive) role of misunderstandings to enable social interaction by introducing the concept of "working misunderstandings" (Bohannan, 1964:12). A literature review portraying how anthropologists and scholars from other disciplines have utilised the concept for their research constitutes the basis for the proposition to structure these various applications of "working misunderstanding" into a logical quadrant model. The suggested quadrant typology aims to facilitate a more precise discussion on working misunderstandings and their systematic employment in ethnographic research. The framework proposes a quadrant consisting of two analytical dimensions based on the differentiation of firstly the involved parties (locus) and secondly the level of intentionality (modus) of working misunderstandings. The ethnographic example deals with a working misunderstanding between the anthropologist and her interlocutors on "collaboration" in the context of cross-departmental project work in a professional servicing firm in Mumbai (India). The case is positioned within the suggested framework under the modus of intentional working misunderstandings, a seemingly marginalised and/or under-reflected category in ethnographic accounts.

\section{Working misunderstandings and ethnographic insight}

The term "working misunderstanding" in the context of an ethnographic research was brought up first by Paul Bohannan in his analysis of the characteristics of colonialism in Africa.

In an African colony, then, the political and economic situation was assessed by the European rulers in terms of European culture; the same situation was assessed by Africans in terms of their various African cultures. Their common heritage and 
their common humanity assured that for some matters the two evaluations were complementary. Just as surely their separate histories led them to view other matters divergently. [...] Such is the nature of the "working misunderstanding". [...] There were two sides and neither really knew the "codes" - the connotations of word and deed - in which the other group perceived the situation, valued it, communicated about it, and acted. (Bohannan, 1964: 12-13)

According to Bohannan, the political and economic structure of colonialism was possible, because of the differing interpretations of the situation by the colonisers and the colonised and remained "working" as long as the two systems were kept apart (ibid.: 25). Or, as Marshall Sahlins put it more precisely: "We have to deal rather with a parallel encoding [...] as a 'working misunderstanding.' It is a sort of symbolic serendipity, or at least a congruent attribution from two different cultural orders of a special meaningful value to the same event." (Sahlins, 1982: 82) Hence, a working misunderstanding arises, when at least two social systems are interacting with each other on the basis of a common situation, term or activity. Both systems are interpreting the situation, i.e. selecting the understanding of it, in terms of their own system-specific context, which might be fundamentally different to the other's interpretation. But the situation can be re-contextualised so that it "makes sense" within the realms of one's own system (Gershon, 2005:103) and enables continuity of interaction. This interaction across social systems is in function not only despite, but much more due to these working misunderstandings. They can be seen as the bridge needed between different systems to enable an uninterrupted (i.e. successful) interaction, hence to remain intact and "working".

Such working misunderstandings have been employed by a number of scholars for their analysis, both within anthropology (Cole, 2014; Dorward, 1974; Losonczy and Mesturini Cappo, 2014; Reed, 2006; Watkins and Swidler, 2013; Wijsen and Tanner, 2008) as well as other disciplines such as Sociology (Jaffee, 2012), Law (Chen-Wishart, 2013) or History (Iliffe, 1979; Spear, 2003). The term "productive misunderstanding" is used in an almost synonymous manner in ethnographic studies (Gershon, 2005; Livingston, 2007; Monteiro and Keating, 2009; Tsing, 2005) or as "malentendu productif" in direct translation of the term in French (Chabloz, 2007: 34; Papinot, 2007). Others have drawn on the concept of structured misunderstandings (Servais and Servais, 2009), a "malentendu bien entendu" (La Cecla, 2002), or have not used a specified term to illustrate the role of misunderstanding as means of supporting successful social interaction (Durrenberger, 1975; Fabian, 1995). Guido Sprenger (this volume) proposes to differentiate structured from unstructured misunderstandings, by which the former is based on the existence of a shared mode of communication, a term or set of terms which have a partial semantic overlap and are used by both parties. Unstructured misunderstandings in contrast rely on serendipity in order to remain working, such as the example of Sahlins (1982).

These accounts of working misunderstandings illustrate the positive nature of misunderstandings and their potential to contribute to successful social interaction. The application of the concept, however, remains far from a coherent terminology and/or analytical direction. With publications spanning half a century, working misunderstandings are obviously a longer-lasting topic of academic interest. Yet, no 
effort has been made so far to structure the discourse on analytical positions pertaining to working misunderstandings for which this article seeks to propose a starting point.

\section{Working misunderstanding as analytical category}

To approach a common ground for discussion on working misunderstandings as an analytical category for ethnographic insight I will draw exemplarily on a selection of the works mentioned above and derive from these accounts the two analytical dimensions for working misunderstandings on which the suggested quadrant typology framework builds on: locus and modus.

The dimension locus differentiates working misunderstandings into the ones arising in-between interlocutors versus those encountered between anthropologist and interlocutor. Each one is illustrated with three examples from the existing body of ethnographic studies in the following section (3.1.). Section 3.2. addresses the modus-dimension which distinguishes working misunderstandings along accounts of intentionality and non-intentionality on the basis of further ethnographic examples derived from literature. Both dimensions (locus and modus) are then combined into a quadrant typology model into which the current body of literature can be structured (3.3.). This suggested analytical framework of working misunderstandings is applied in section 4 to the ethnographic case study from the fieldwork in Mumbai's office environment which will address a seemingly blank category within the quadrant.

\subsection{The Locus : Misunderstanding amongst interlocutors or between interlocutors and anthropologist}

Watkins and Swidler (2013) illustrate in their work how the different parties involved in HIV prevention (donors, brokers and villagers) are operating on a narrow set of program labels, or "themes that make everyone happy", as they enable all agents an attachment of their different meaning. Intervention programs aiming at "fighting stigma" for example can appeal to religiously motivated donors, as it enables HIV intervention without having to mention issues of sexual protection methods, while for the (in this case Malawian) communities "fighting stigma" merely iterates their reciprocal obligations to kin. Although the theme means something different for each of the involved parties, all can work together under it. This functions because the common theme allows for all parties to collaborate without the need to confront the different meanings attached to the same words (ibid.: 203).

Similarly, Anna Tsing collected stories of the different key players to recapitulate a successful anti-logging campaign in a Meratus village in Indonesia and she realised that all parties seemed to describe different events to her, corresponding to their differing commitments to nature. It was not despite but because of the misunderstandings between village elders, provincial nature lovers and national environmental activists that they were able to collaborate successfully and to accomplish the campaign's goal to get the logging company removed from the village (Tsing, 2005: $245 \mathrm{ff}$ ).

A further ethnographic example for the productivity of misunderstandings is given by Marko Monteiro and Elisabeth Keating (2009) on collaboration in an interdisciplinary cancer research team with scientists' expertise ranging from computer 
science, biomedical engineering, to applied mathematics and medicine. By tracing communication at the team's weekly meetings they illustrate how strategies such as the "eyeball norm" (presenting data in a way it looks plausible to everyone) are used to facilitate successful collaboration without coming to a shared understanding across the disciplines (ibid.: 9).

These three studies refer to the same locus of working misunderstanding as all authors analyse how a working misunderstanding supports the interaction between their interlocutors. They illustrate the successful functioning of cooperation between different parties despite incongruent or even potentially conflicting pre-dispositions and worldviews, such as in the example of the "fighting stigma" - theme in HIV prevention. The working misunderstanding discussed in the three studies related to topics the researchers were able to examine without being themselves part of the misunderstanding. The authors seemed to either have no strong own ascriptions to the term or situation of misunderstanding between the interlocutors, or at least the connection to the anthropologist's own understanding was not salient in the analysis.

But working misunderstandings can have a different locus and arise between an anthropologist and his or her interlocutors. This case has seldom been analysed in the literature and this article's case study certainly can contribute to fill that gap. The following three studies have, however, already addressed the issue.

Johannes Fabian (1995) for example describes how he assumed the Swahili term muzungu to apply to a white man, when one of his interlocutors told him about a muzungu who had joined a religious movement in Zimbabwe. Only years later he realised that it was the female African-American anthropologist Benetta Jules-Rosette to whom his interlocutor referred to as muzungu in the interview (ibid.: 43). The term muzungu for the informant was referring to a non-African, while Fabian inferred a white, male person, despite being aware that the strict lexical meaning is more extensive and that Swahili does not mark gender. But, as Fabian points out, also as ethnographers we have to accept misunderstandings and "settle for a version we can live with" (ibid.: 44) in order to continue, to have the communication going on, to have the cross-system interaction in function.

In a methodological reflection on the application of photo-elicitation interviews Christian Papinot describes how the misunderstanding between himself and his interlocutors on the meaning of photos proved productive. He had taken a series of close-up photographs of decoratively painted inscriptions and motives on public transport buses in northern Madagascar with the intention to utilise them in his interviews. With the photos he wanted to trace the discourse on interpretations of these motives with his interlocutors. But his understanding of the photos as a supportive tool of enquiry differed significantly from the understanding of his interlocutors. Using photographs as mere support for interviews collided with the Malagasy social definition of a photograph (Papinot 2007: 83). Consequently, the images he showed did not lead to interpretations of the decorations as Papinot had expected: the close-up, seemingly truncated images were instead perceived as an enigma to identify the driver of the vehicle. This misunderstanding on the purpose of the photos was productive as it allowed for a conversation leading to the uncovering of a connection of the decorative elements with the rivalry going on between the vehicle drivers (ibid.: 84). 
A last example relates to the reflection of Anna Tsing that understandings of a forest can be social rather than naturalist, which she had learned in the course of her fieldwork. She realised that her view on the Meratus forests was steered from a naturalist perspective, so that she appreciated the variety of species or the forest views from a mountain ridge. Her interlocutors' understanding of the forest, however, was one where "individuals and households traced their histories: House posts resprouted into trees. Forest trees grew back from old swiddens." (2005: xi). Here the anthropologist him/herself becomes part of the discourse as one's own understanding of a concept, term or situation is incongruent to the interlocutors' understanding(s).

The detection of misunderstandings in general is neither surprising nor rare - it presents rather part and parcel of everyday fieldwork and is of value as it renders the perception that one is in dialogue with agents of a group with a different framework than one's own. The working misunderstanding, however, provides here an additional level of insight, as it not only highlights a distinction to the understandings of the other party. It also emphasises the existing layers of similarity as the actions resulting from the understanding of a situation are similar or at least comprehensible for the other system despite differing understandings. This is why the misunderstanding continues un-noticed up to the point when the behavior reveals the difference. The "working" aspects indicate up to which point a more or less superficial congruence between one's own ascriptions and the interlocutors' exists.

\subsection{The Modus: tracing the intentional/non-intentional}

The literature examples discussed in 3.1. centred either on the analysis of a working misunderstanding between interlocutors or - in the latter case - between anthropologist and interlocutors. But despite their difference in locus one can highlight a commonality in terms of working misunderstandings: their non-intentionality (modus). The working misunderstanding happened unconsciously and unintended, as far as one could assess the situation from the information provided. Neither of the involved parties seemed to have insights into the others' ascriptions; they did not actively shape their actions for the misunderstandings to remain working.

Working misunderstandings, however, are not always kept "working" solely on the basis of an incidental, undiscovered, semantic overlap across the interacting systems. While Sahlins (1982) argued in his account of Captain Cook for a working misunderstanding between Cook and the Hawaiians, explaining the killing of Cook not as a necessary but possible consequence of the working misunderstanding, he primarily wanted to explain the behaviour of the Hawaiians for whom Captain Cooks behaviour fitted well to their own context (Reed, 2006: 157). Isaac Reed instead argues that Cook, on his account might have understood the role in which the Hawaiians have seen him very well and adjusted his own behaviour to avoid being unmasked as a human being by them ( e.g. by refraining from women as opposed to his crew). In order to keep the misunderstanding working "each side played certain roles in the other sides drama" (ibid:: 158).

Similarly, in her study on Malagasy women married to French men Jennifer Cole (2014) illustrates how these women played strategically on ambiguities in Malagasy kinship as a working misunderstanding to keep the complex interactions between the French and Malagasy family systems intact: 
She claimed that the French term sœur (sister) and the Malagasy term rahavavy (sister) referred to the same semantic field, even though she knew that rahavavy covered a wider range of kin than her husband would have recognised as sœur. She built a working mis/understanding premised on the gap between Malagasy and French definitions of the term sister to smuggle in - literally - a relative whom she deemed important but whom Pierre [her husband] would almost certainly not have counted. (ibid.: 541)

The ability to actively play on such unarticulated ambiguities and semantic overlaps is a particularly interesting aspect of analysis in terms of working misunderstandings, as it requires a certain level of knowledge about the other interacting party and conscious shaping of one's own action in line with the other's expectations.

Anne-Marie Losonczy and Silvia Mesturini Cappo illustrate this in their study on the example of two Ayahuasca shamans in Iquitos (Peru): one of them fails to attract occidental clients due to his inability to play on the working misunderstandings on shamanism between local/mestizo concepts and western ideas, which the other one apparently does very well, due to his experience from travel to Europe and his frequent contacts with occidental tourists and apprentices (2014: 124-26). The shaman was therefore able to actively shape his actions along similarities in the ascriptions on shamanism between the two social systems for the misunderstanding to remain working and to prevent notions of dissonance with his European apprentices.

These three accounts of working misunderstandings contrast the previous ones insofar as the interlocutors shaped their behaviour in the given situations actively and intentionally. I therefore suggest to structure working misunderstandings along a second dimension which differentiates between notions of intentionality and non-intentionality. I will refer to this dimension as modus in the following framework model.

\subsection{Towards a framework of working misunderstandings}

Section 3.2. has illustrated how the concept of working misunderstandings as analytical category can be separated into two different dimensions, the locus and the modus. These two dimensions as derived from existing applications of working misunderstandings in ethnographic analysis are proposed to be taken as a categorical orientation to structure the existing body of research on the concept as well as an opportunity to foster future discourses about it. To account for the interdependencies of the two analytical dimensions while retaining a certain level of lucidity I suggest to arrange them into a quadrant along which the examples discussed can be allocated, notwithstanding the risk of suggesting simplicity (Fig. 1).

Given the several accounts of working misunderstandings, it becomes apparent that in general the locus anthropologist $<>$ interlocutor is an under-represented category in ethnographic literature, to which the works in this volume will fill a significant gap. Accounts dealing with the reflection on intentional modi of working misunderstandings between the anthropologist and his or her interlocutors constitute a seemingly marginalised category. This category refers to working misunderstandings in which the anthropologist is (at least partially) aware of the differing ascriptions of his or her interlocutors to a term or situation in contrast to his/her own understanding, and is actively shaping his/her behaviour to keep the misunderstanding working. Such a situation can of course also occur in the opposite direction when interlocutors modify 
their actions to comply with the understanding of the anthropologist - the uncovering of such a working misunderstanding is difficult and has not appeared in the literature review.

Fig.1. Framework of working misunderstandings as analytical categories.

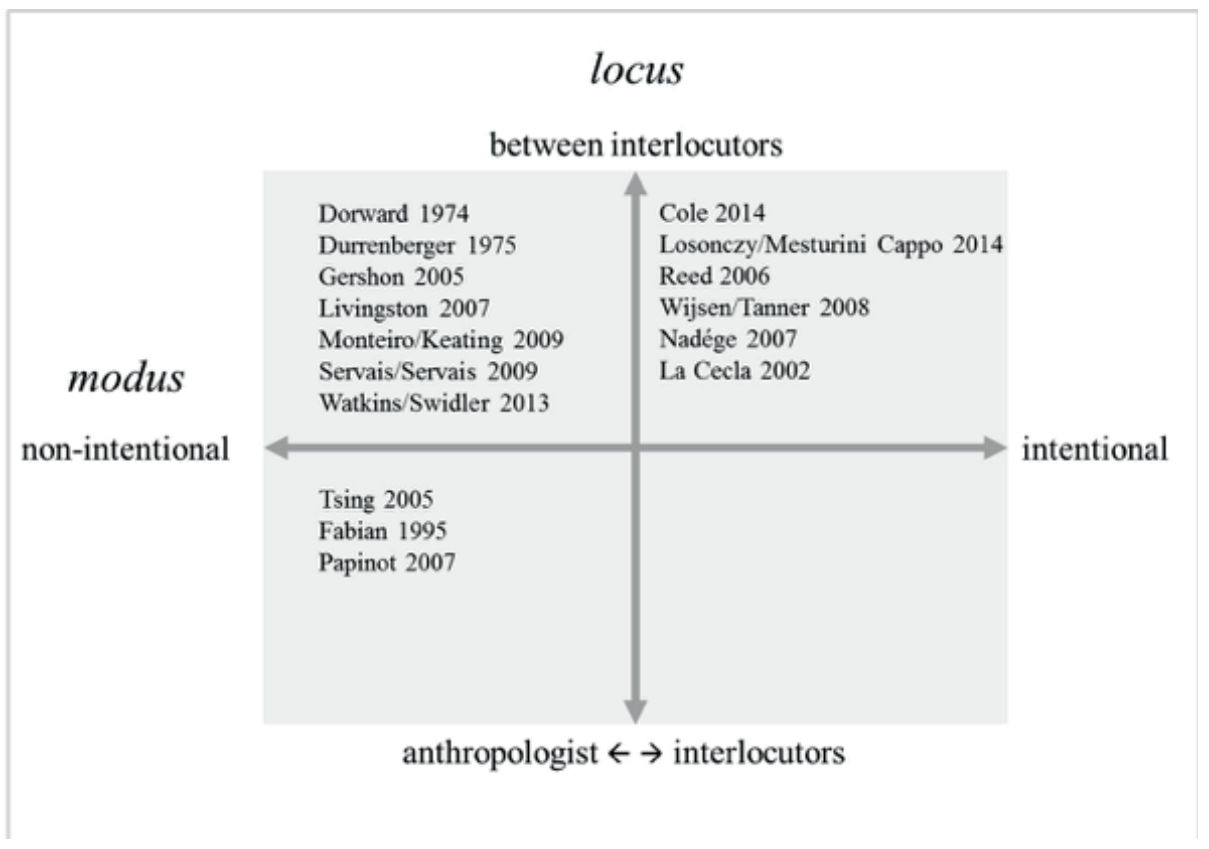

The following case from my fieldwork in a professional servicing firm in Mumbai fills the gap in the quadrant model as it deals with a working misunderstanding in the locus anthropologist $<>$ interlocutor and traces the boundary-line between the intentional and non-intentional modus-dimension.

\section{Working misunderstandings on "collaboration" in corporate offices}

In line with this volume's theme of misunderstandings encountered between anthropologists and circumstances arising during fieldwork and/or ethnographic analysis, the categorical focus of analysis lays here in the working misunderstanding between the anthropologist and her interlocutors. It concentrates on the disparate understandings of "collaboration" in the context of project work, which remained undetected and working for the first phase of fieldwork.

\subsection{Changing perspectives: multi-sited fieldwork}

The case study is based on multi-sited fieldwork (Marcus 1995: 106) carried out over the duration of twelve months in 2013/14 at the three offices of a westernorigin multinational professional servicing firm in Mumbai (India) with a total of 
approximately 800 employees of various hierarchy levels and designations. The offices differ significantly in size (from 50 to 450 employees) and facility level (from sleek corporate to basic suburban). All employees, however, contribute to the value chain of the organisation that defines the formal relationship between them and the need for collaboration across designations and localities. The company offers consultancy and advice for their clients on relevant business decisions, which is usually organised in the form of a project. Within each office, a multi-sited approach was also applied on the micro-level by working in a selection of divisions and teams within each office. The primary method of data collection applied was "shadowing", a variant of participant observation, which has proven most useful in the office context (McDonald, 2005: 457). This meant to trace the daily work patterns of employees I accompanied for an average of three consecutive workdays all across the office floor, meeting rooms and cafeteria breaks, but also to follow along to other offices and activities with their work colleagues such as wedding receptions, team dinners and weekend coffees. However, during a later phase of fieldwork, familiarity with a large number of employees and business processes allowed employing a different strategy to change the perspective on the field: I "attached myself" to client projects and went along with them throughout their lifetime to different agents in different departments and office locations. Whoever was working on the project - I came together with it to observe the work steps being done there. Although not a material object as such, the project was the central commodity around which the departments geared up their processes. This alteration in strategy to "follow the thing" (Marcus, 1995: 107) allowed for a perspective on everyday work which was strikingly different to the previous one I had taken of an employee with the various projects they usually worked on in parallel. It further helped to gain insight into the employee's notions of collaboration in relation to the very same project and the information around it.

\subsection{Discovering "collaboration"}

Right at the beginning of my fieldwork, I was allowed to join in on the company's "new employee's introduction training", a two-day-seminar in which senior managers presented the specialties of the different departments and representatives from the human resources team welcomed the new hires to the "organisational family". Apart from the department specific facts, advices given most frequently during those two days called for "boundaryless behaviour" in the office and to "share information openly and freely across the organisation". Along with these advices came a few collaboration activation games, such as passing on a sugar cube along a line of team members with chopsticks to emphasize on the importance of each team member for the success of the entire task. And indeed, the physical set up of the main office for 450 employees stood in congruence with these messages: it was a very stringent realisation of an open office, with no walls or individual cabins for managers. All employees had exactly the same desks, regardless of their designation and several semi-open chat corners or glass-walled meeting rooms provided for interactive work spaces. This was very similar to the settings popular management books advice for to create a "Culture of Collaboration" (Rosen, 2007: 116) and also provided for a notion of the organisation as a single system with transparency and egalitarianism as central values. These facts seemed to affirm my understanding of it, which I thought, was coined by ideas of mutual 
knowledge exchange and common access to information. Following my understanding of collaboration the question in focus therefore was how to achieve the maximum amount of shared knowledge across the collaborating parties within the organisation as this would allow for the most beneficial work results (Squires and Van De Vanter, 2013: 298). This might partially be related to my work experience of over ten years as an IT professional managing software implementations with the aim to support exactly this idea of maximising information availability across organisations. Current discourses on collaboration in Information Systems Research have even more focused on the topic with the emergence of Cloud data storage technologies and collaboration software innovations (Kogan and Muller, 2006; Li et al., 2012; Shah, 2014).

During the early weeks of my research when I accompanied my first team - colleagues of the client consulting department - I observed how the team members worked closely together on a task. Sometimes this collaboration was almost literally performed with two or three colleagues sitting together lined up at the same desk discussing and developing jointly presentations, documentation and emails to be sent out to clients. They frequently sought advice from each other and just called across to the next line of desks in case the colleague was not sitting next to them. So what I saw and heard about in these first weeks was close interaction with a high communication density between the team members.

The colleagues of the next team I accompanied had the task to support the first one by organising the acquisition of material and data needed for their advice to the clients. When I asked how they managed the different client projects which are handed over from the consulting teams, my interlocutors patiently explained to me the various documents from which they drew the project information and in which format they would store new updates in shared databases to be reviewed by the other teams. To ensure to comply with the compulsory activities in the mandated sequence along a project process, most colleagues of the team maintained elaborated lists of 20-25 "to do's" for each of the projects they managed. All of these "to do's" were centred around exchange of project-related information or status updates on the project's progress. This did not only correspond to the "boundaryless behaviour" requested from the managers at the introduction training, but also to my own ideas of collaboration encompassing the assumption on the most possible free access to information along the value chain. I remained fully engaged collecting very detailed data about the various technicalities of the project process. The working misunderstanding on collaboration worked very well and I was not aware of any difference in the understanding of collaboration between the employees and myself.

The misunderstanding would remain working for several weeks longer, until I accompanied Naveed, who happened to work on a project I identified after some time as one that had been initiated by a client in the consulting team during my stint there. It had taken me almost half of the day to realise that it was the same project, due to the differences in the information Naveed seemed to have about it and what I thought to have picked up in the first team. While the consulting team member had given me an elaborated account on the strategic intent and the type of advice the client was looking for, my interlocutor now explained to me a few sentence-long, cut-down version of it, focusing on the key data needed for the project management team. The information gap became most clearly apparent when it came to timelines: Naveed seemed to have 
no information regarding the date by when the client would expect the project to be finished and presented, which I recalled had been agreed on via Email. He had just gotten a deadline by when he would have to complete his task list. For a while I kept on wondering if I had simply done a poor job on taking notes regarding the facts about the project, mixed up client's names or just wasn't familiar enough yet with the different databases and tools used for collaboration. Despite assuring myself that none of this seemed to be the case, I still assumed my notion of collaboration to be valid. In correspondence to the open office environment without any wall separating teams and departments, I remained fully focused on discovering how the information on the project in the first team could get reduced and changed across a 15-metre stretch of desks despite explicit processes, databases and the "to do"-lists. It was only a few hours later when I heard and saw how Naveed gave his supporting sub-teams a much shorter project completion deadline than the one he was actually working towards. That was the moment I realised that different notions of collaboration were at play between myself and my interlocutors.

\subsection{Collaborating for achievement}

As I continued to move to different teams and departments all contributing to the client projects, I encountered similar patterns of knowledge management and control. When I later traced the individual work steps along a client project, I realised that only the senior consulting team members are involved directly in meetings and communication with the client, which corresponded to the perceived hierarchy structure in the office. All other teams along the value chain instead got briefed by the previous one and were provided with timelines by when they would have to have their task completed for the project. One consulting team member explained to me:

You know, the data preparation teams will be late in any case, because the execution guys will only start working when the deadline comes near... So I give the project managers shorter timelines, keeping the buffer for me. Otherwise I will be the one sitting there doing long hours to deliver to the client on time.

The notions of collaboration in this division were geared up along questions of the best strategy to manoeuvre the project information (or parts of it) to achieve the goal of a successful project delivery without escalations. The individual teams and their actors were not part of one organisational system, but individual ones, which were actively selecting only that aspect of information about the project they decided to be important for the next team. There was even another twist to how the employees approached the project information in relation to collaboration: the different teams suspected that the information they had gotten most likely had been edited by the previous team in a way they perceived appropriate to reach the goal of on-time delivery. A project manager commented upon reviewing the briefing on a new project she was handed over with urgent timelines: "Those consultants play oversmart on us. They have some 5-10 days buffer, but don't tell us. And we only have unnecessary pressure, which we need to push down to the other teams". She was perfectly aware of the fact that she was kept in the dark about the actual delivery dates and that they most likely would be much later than she had been told. Yet, she passed on an even shorter deadline to the next team, about which the colleague in the support team told me: "We sometimes have to commit to unrealistic timelines, when they tell us client needs it. And everybody knows 
it's unachievable, even consultants. But project goes ahead only and we deliver with delay".

The working misunderstanding between myself and my interlocutors in the organisation was that my notion of collaboration assumed transparent and equally available access to the project's information within the same social system. This was affirmed by the "officially communicated" idea of collaboration by organisation's leadership team in the new joiner's training and the physical open-office set up, while everyday working praxis fostered the emergence of individual teams along the value chain. Consequently, the observed communication processes showed a selection of information from the hierarchically higher team (i.e. the one which is closer to the client) on what the next team has to know, such as the team-specific project deadlines. The selection of understanding within the next team on this information, however, might have been different from what the previous team had expected: the next team factored this pre-selection of information and produced the information within their own sub-system as "yes, that's the date we have been given, but they anyhow have planned some buffer, so the real deadline must be later". On the very practical side, this approach to collaboration led to a rather unexpected situation during fieldwork: by moving between the different teams in this multi-sited corporate setting, I frequently had gained significantly more knowledge about the individual projects than the employees in the individual teams officially shared with each other. This opened up a number of considerations on knowledge management during fieldwork and how this relates to an intentional working misunderstanding.

Through this fieldwork approach I learned about the individual actor's different and quite restricted views on and within the organisation, even within the same open plan office space, realising that grasping the emic perspective meant "switching off" parts of my knowledge. Being part of one team meant to ignore certain aspects of the work process that were central and taken-for-granted in the other one and vice versa. Making use of my full knowledge about certain projects or circumstances and sharing it with the different individuals would have meant to alter the preconditions of the collaboration situation significantly, as especially this information imparity constituted the structures I was analysing. Hannerz (2003: 210) asserts that with this new problematisation of the 'native' and ethnographer's knowledge "we have moved away from the classic field work model". It is not primarily about gaining the maximum knowledge; it is much more about knowing what the individuals don't know in comparison to others in the organisation.

Once I had discovered the diverging notions of collaboration between myself and my interlocutors through the multi-sited fieldwork approach, the situation demanded me to take a decision on how I would interact with them in the context of project collaboration. If I openly shared the knowledge I had gained about the various projects by moving through the different teams and departments I might have brought the carefully crafted collaboration system to a point of unravelling. The alternative was to play on the ambiguities at hand, just as my interlocutors did, to keep the misunderstanding working. As outlined in the next section I decided for the latter and shifted from the so far non-intentional to an intentional modus of working misunderstanding. 


\subsection{Moving into the blank spot: from non-intentional to intentional working misunderstanding}

As much as my interlocutors were perfectly aware of the strategic information concealment between the different teams and played their role, so I assumed to play mine in "the other side's drama" (Reed, 2006:158) by not sharing all the knowledge I had about the project. While the early phase of my analysis on collaboration patterns clearly can be categorised as a non-intentional working misunderstanding between the anthropologist and the interlocutors, the situation changed as soon as I gained more insights into the working practices on project collaboration shaping each team's strategic information selection. From that point onwards, I was able to realise on the ambiguities at play regarding the circulating project information and to manage my own knowledge carefully to gear my utterances and questions along the knowledge levels of my respective interlocutors. So through my actions I actively and intentionally kept the misunderstanding working.

I did not directly voice my understanding of collaboration in contrast to the lived praxis encountered with my interlocutors. I can only speculate on the reflections of my interlocutors on this, as I did not create a dissonance in their expected behaviour, or at least it did not become salient enough to be discussed. It was only during the last research phase when I followed along the project execution process and frequently changed desks, that one of the consultants with whom I was sitting leaned over to me in a conspirative manner and uttered with a low voice: "I know you probably shouldn't tell me, but I saw you sitting with Neha [the project manager] this morning, so you must have talked about project GREEN. Accha [okay], at least tell me if it's on track, I fear something is boiling up there..."

Hence it was not only me who played the role. At least this colleague was also quite aware that I had understood the notion of collaboration at play in this organisation and shaped my behaviour accordingly. The way he posed his question further suggested that he was equally aware that he violated the rules of the game by drawing on my knowledge to get information which was not selected for him by the other team. Acting according to my own understanding on collaboration would have meant to tell my interlocutor that I had accompanied Neha in the morning during the several phone calls to her team-leads of the three work streams about the status of their work. And that one of them announced the risk of a potential delay of several days, which Neha decided not to pass on directly to the consulting team, as she was positive it would be fixed with a bit of overtime work. Instead I uttered something indifferent about many projects at play right now with all their individual progress levels and challenges. It was a response that fitted into the working practice and consequently he didn't iterate his question again, but continued to focus our conversation on an urgent client request demanding his full attention for the rest of the day.

Along with the advancement of my own insight on the misunderstanding I learnt to map out the boundaries of knowledge exchange and the distribution of the shares of information across the organisation. I also learnt which parts of my own information about a specific project I had to "switch off" in which team to not impede the set up shaped by my interlocutor's concept of collaboration. I learnt where to be vague about my project knowledge when accompanying interlocutors from various teams, 
although my own understanding of collaboration actually would have proposed a different behaviour. I had moved into the intentional modus of misunderstanding to keep it working.

\subsection{Working (with) misunderstanding}

Given the predispositions of my professional background as a western IT specialist with a deep-rooted commitment to information provision based on egalitarian ideas on knowledge-sharing, it is not a pure coincidence that I found my understanding of collaboration mirrored in the organisation's official idea on collaboration. This congruence might have fostered the misunderstanding to persist unidentified throughout several weeks of intensive fieldwork. The working aspect of the misunderstanding lays in the fact that I was able to apply my notion of collaboration in terms of knowledge sharing for the initial phase of fieldwork without encountering dissonances to the observed practice: I accompanied my interlocutors to briefing meetings or conference calls, and eagerly absorbed their explanations on the various databases bearing a project's information. At that level of insight, my idea of collaboration seemed to fit to the working practices I observed. Consequently I collected data on how the employees in and across the various teams shared project information, via which communication channels and functions. Only after having been in the organisation for a longer time I got into a situation where I was able to relate the information available to the interlocutor I accompanied on a specific project to the knowledge I had gained about the very same project in the other team. Reaching this level of comprehension denoted the moment when I gained sufficient insight into the working practices to realise a discrepancy between my understanding of collaboration and the working practices I was witnessing.

\section{Conclusion}

I have shown in this paper that "working misunderstanding" with its productive quality to facilitate social interaction bears rather opportunities than threats for ethnographic insight and that the concept has already been applied across various disciplines over the last five decades. The literature review has revealed that the diverging applications of working misunderstandings in the ethnographic research can be allocated on a quadrant model consisting of two analytical dimensions based on the differentiation of firstly the involved parties (locus) and secondly the level of intentionality (modus) of working misunderstandings. While acknowledging the risk of oversimplification of such a complex topic through the quadrant structure, I propose this model as a starting point to foster a streamlined discussion leading to coherent terminology and/or analytical direction of working misunderstandings.

The case study has illustrated a working misunderstanding between the anthropologist and her interlocutors on the example of "collaboration": in spite of factually diverging notions of it, the interaction between me and my interlocutors was possible without encountering dissonances and we discussed various screens within project documentation databases and other tools used for their work. The information about the project collaboration practices at the organisation allowed for a re-contextualisation of the situation (Gershon, 2005:103) so that it proved meaningful 
within the realms of my own concept of collaboration. This "parallel encoding" (Sahlins, 1982) enabled undisturbed continuity of interaction with my interlocutors due to the working misunderstanding. It remained uncovered as long as my insight into the other system was limited to the visibility of how information was exchanged - which matched my expectations.

Gaining sufficient insight into what was communicated for project collaboration delineated my "point of unravelling" (Reed, 2006), that moment when I realised the incongruence between my notion of collaboration and how my interlocutors executed it. Until that moment the working misunderstanding could be allocated within quadrant typology framework under the locus anthropologist $<>$ interlocutors and the nonintentional modus. After the point of unravelling, my case study experienced a shift towards an intentional modus of working misunderstanding. In this later phase of fieldwork I consciously shaped my behaviour towards the ambiguities at play on project knowledge to comply with my interlocutors' notions and practices of collaboration. Therefore it can be positioned in the blank spot of the quadrant - in the category of intentional working misunderstandings between anthropologist and interlocutors.

This seemingly marginalised category is insofar an analytically interesting one as it is marked by the formation of the boundary-line (La Cecla, 2002:14) between the anthropologist's understanding of the concept and the interlocutor's views about it. The limits of intentionality within this category of working misunderstandings are at this point not yet sharply defined. How to draw the line towards studies on practices of deception or "misrepresentation" (Strauss, 1993:182) is certainly a question which opens an even wider focus on working misunderstandings as a research field. The systematic classification of working misunderstandings along the two dimensions in the typology quadrant offers, however, an opportunity to concretise such questions.

\section{References}

Bohannan, Paul, 1964. Africa and Africans. New York: The Natural History Press.

Chabloz, Nadège. 2007. "Le malentendu. Les rencontres paradoxales du 'tourisme solidaire", Actes de la recherche en sciences sociales, 107 (5), pp. 32-47.

Chen-Wishart, Mindy, 2013. "Legal transplant and undue influence: Lost in translation or a working misunderstanding?", International and Comparative Law Quarterly, 62 (1), pp. 1-30.

Cole, Jennifer, 2014. "Working mis/understandings: The tangled relationship between kinship, FrancoMalagasy binational marriages, and the French state", Cultural Anthropology, 29 (3), pp. 527-551.

DorwARD, David, 1974. "Ethnography and administration: A study of Anglo-tiv 'working misunderstanding"”, The Journal of African History, 15 (3), pp. 457-477.

Durrenberger, Paul, 1975. "Understanding a misunderstanding: Thai-Lisu relations in Northern Thailand", Anthropological Quarterly, 48 (2), pp. 106-120.

FABIAN, Johannes, 1995. "Ethnographic misunderstanding and the perils of context", in Fabian Johannes, Anthropology with an Attitude. Critical Essays, pp. 33-52. Stanford: Stanford University Press.

Gershon, Ilana, 2005. "Seeing like a system: Luhman for anthropologists”, Anthropological Theory, 5 (2), pp. 99-116.

Hannerz, Ulf, 2003. "Being there... and there... and there! Reflections on multi-site ethnography", Ethnography, 4 (2), pp. 201-216.

ILIFFE, John, 1979. A modern history of Tanganyika. Cambridge: Cambdridge University Press. 
JAFFEE, Daniel, 2012. "Weak coffee: Certification and co-optation in the fair trade movement", Social Problems, 59 (1), pp. 94-116.

Kogan, Sandra and Michael MulLer, 2006. "Ethnographic study of collaborative knowledge work", IBM Systems Journal, 45 (4), pp. 759-771.

La Cecla, Franco, 2002. Le malentendu. Paris: Editions Balland.

Livingston, Julie, 2007. "Productive misunderstandings and the dynamism of plural medicine in mid-century Bechuanaland", Journal of Southern African Studies, 33 (4), pp. 801-810.

Losonczy, Anne-Marie, and Silvia Mesturini CAPpo, 2014. "Ritualized Misunderstanding Between Uncertainty, Agreement, and Rupture. Communication Patterns in Euro-American Ayahuasca Ritual Interactions", in Beatriz Caiuby Labate and Clancy Cavner (eds), Ayahuasca Shamanism in the Amazon and Beyond, pp. 106-128. London: Oxford University Press. (Retrieved from Oxford Scholarship Online)

MARCus, George E., 1995. "Ethnography in/of the world system: The emergence of multi-sited ethnography», Annual Review of Anthropology, 24 (1), pp. 95-117.

McDonAlD, Seonaidh, 2005. "Studying actions in context: a qualitative shadowing method for organizational research", Qualitative Research, 5 (4), pp. 455-473.

Monteiro, Marko, and Elizabeth Keating, 2009. "Managing misunderstandings: The role of language in interdisciplinary scientific collaboration”, Science Communication, 31 (1), pp. 6-28.

PAPINOT, Christian, 2007. 'Le 'malentendu productif': Réflexion sur la photographie comme support d'entretien», Ethnologie française, 37 (1), pp. 79-86.

REED, Isaac, 2006. "Social dramas, shipwrecks, and cockfights: Conflict and complicity in social performance", in Jeffrey Alexander, Bernhard Giesen, and Jason Mast, (eds), Social performance: symbolic action, cultural pragmatics, and ritual, pp. 146-167. Cambridge: Cambridge Univ. Press.

Rosen, Evan, 2007. The culture of collaboration. Maximizing time, talend and tools to create value in the global economy. San Francisco: Red Ape.

SAHLINS, Marshall, 1982. "The apotheosis of Captain Cook", in Michael Izard and Pierre Smith (eds), Between belief and transgression: structuralist essays in religion, history, and myth, pp. 73-102. Chicago: University of Chicago Press.

Servais, Christine, and Véronique Servais, 2009. "Le malentendu comme structure de la communication", Questions de communication, 15, pp. 21-49.

Sнан, Chirag, 2014. "Collaborative information seeking”, Journal of the Association for Information Science and Technology, 65 (2), pp. 215-236.

SPEAR, Thomas 2003. "Neo-traditionalism and the limits of invention in British colonial Africa", The Journal of African History, 44 (1), pp. 3-27.

Squires, Susan, and Michael L. Van De Vanter, 2013. "Communities of practice”, in Douglas Caulkins and Ann Jordan (eds), A Companion to organizational Anthropology, pp. 289-310. Oxford: John Wiley and Sons, Ltd.

Strauss, Anselm, 1993. Continual permutations of action. New York: de Gruyter.

Tsing, Anna Lowenhaupt 2005. Friction: an ethnography of global connection. Princeton: Princeton University Press.

WAtKIns, Susan Cotts, and Ann Swidler, 2013. "Working misunderstandings: Donors, brokers, and villagers in Africa's AIDS industry”, Population and Development Review, 38, pp. 197-218.

Wijsen, Frans, and Ralph Tanner, 2008. "The limitations of an ecumenical language: The case of KiSwahili”, Anthropos, 103 (2), pp. 549-554. 